\title{
Experimental Scurvy. Its Employment for the Study of Intercellular Substances
}

By S. Burt Wolbach, The Children's Medical Centre, Boston, Massachusetts, U.S.A.

The principal purpose of this paper is to show how knowledge of intercellular materials can be increased by the study of the easily observable histological sequences which take place during the induction and repair of experimental scurvy in guineapigs. This tractable animal, which has been of great service to medical science in many other ways, deserves grateful acknowledgement because it cannot synthesize ascorbic acid.

In I923, Wolbach and Howe joined forces in a programme of study having for its objective the pathologic characterization of vitamin deficiency states. Aschoff \& Koch (1919) had written the best account of human scurvy and had emphasized the localization of lesions in all the supporting tissues of the body-in particular, the failure of osteoblasts to function, the absence of new bone formation and the osteoporosis. Höjer's (1924) studies of experimental scurvy, published in 1924 after Howe and I had begun our studies, gave descriptions of scurvy in the guineapig closely similar to those of Aschoff \& Koch in man. Our own studies brought nothing new to light until we studied day by day the reparative sequences which followed the administration of orange juice. The prompt resumption of deposition of the intercellular materials of supporting tissues made crystal clear the fundamental defect responsible for the gross and microscopic lesions of scurvy and gave substance to the speculations and inferences of Aschoff \& Koch and Höjer.

In January 1926, Wolbach \& Howe (1926) characterized the condition of scorbutus as inability of the supporting tissues to produce and maintain intercellular substances'. At that time we had failed to get complete proof that this characterization applied to cartilage because we studied only the costal cartilages instead of the more rapidly growing epiphyseal cartilages of the long bones. Recently, Wolbach \& Maddock (1952) have obtained complete proof that cartilage is affected, as are all supporting tissues, by ascorbic-acid deficiency; in fact, it is a very favourable tissue for the study of the sequences of scurvy and its repair. The epiphyseal cartilage plates of long bones of young guinea-pigs, being avascular and protected on both sides from admixtures with blood, lymph and exudates, probably offer the best material for all techniques available for the study of sequences in cells and matrix formation because fragments can be removed from split unfixed bones for the application of techniques to fixed and unfixed material.

In scurvy in the rapidly growing young guinea-pig, cartilage cells cease to form matrix and assume appearances quite unlike the normal. The cartilage cells become shrunken, irregular in shape, with densely staining nuclei and are separated from one another by material which does not stain with haematoxylin and eosin or the 
Mallory connective-tissue stain. Resumption of matrix formation and normal morphology of the cells occurs promptly after ascorbic-acid therapy (Pl. I, I, 2,3).

Our support for the statement in 1926 that ascorbic acid is necessary for the maintenance of intercellular substances was derived from the study of resorption of bone, a process which leaves an easily readable trail and which takes place, in contrast to rickets, in the presence of an intact mechanism for calcification. Some details of the resorption of bone in scurvy were described by Wolbach (1933). The value of inducing repair and renewed deposition of bone matrix should be emphasized as a great aid in the study of resorption in bones of scorbutic guinea-pigs.

Experiments designed for the study of maintenance of collagen, utilizing the effect of ascorbic-acid deficiency upon scar tissue of healed wounds in guinea-pigs, have been few in number. Hunt (I94I) described the reversion of newly formed collagen to 'an argyrophil precollagenous state'. Pirani \& Levenson (1953) also found that adequate intake of ascorbic acid was necessary 'for the maintenance of scar tissue which has formed in healed wounds over a period of many weeks'. I have been unable to find any other worth-while experimental study of this important problem of the maintenance of uncalcified matrices. More impressive perhaps than experimental evidence are the accounts by Lind (1753) in his famous $A$ Treatise of the Scurvy of the 'breaking out of late wounds' of the arm and the breaking out of healed leg ulcers, and by Walter ( 1748 ) who, in his Anson's Voyage Round the World gives further remarkable accounts of the breakdown of scars of wounds healed for more than 50 years, and of the complete disappearance of 'the callous of a broken bone' so that 'the fracture seemed as if it had never been consolidated'.

Failure of formation of the matrices of cartilage and bone is the simple explanation of the fractures (infractions) at epiphyseal-diaphyseal junctions-the Trümmerfeld zone which Richard Follis (I943) recently showed could be prevented by immobilization. The Gerüstmark zone, a marrowless oedematous-like region of the medulla of bones adjacent to the Trümmerfeld zone, apparently composed of cells of connective-tissue origin derived from the stroma of the marrow according to Aschoff \& Koch (1919), has proved to be an internal callus, the result of infraction, incapable of bone-matrix formation, the cells of osteoblast origin having lost normal morphological appearance and becoming indistinguishable from immature fibroblasts (Wolbach \& Maddock, 1952).

Numerous studies of experimental and human (infant) scurvy made since I 926 warrant the categorical statement that in complete ascorbic-acid deficiency the formation of intercellular materials ceases in fibrous connective tissues, bone, cartilage and dentine. Because new capillary growth ceases, although proliferation of vascular endothelium continues, failure of formation of cement substances may be inferred (Wolbach, 1933). Resumption of deposition of intercellular materials may be seen as early as $24 \mathrm{~h}$ after administration of ascorbic acid.

The rate and amount of production of all intercellular materials appear to have a quantitative relationship to the amount of ascorbic acid administered. Such a relationship for dentine formation in the incisor teeth of guinea-pigs has been proved by Boyle, Bessey \& Howe (1940). The rate of growth of the lower incisor 
teeth of guinea-pigs throughout life is about $2 \mathrm{~mm}$ a week (Boyle et al. r940), and therefore affords a favourable opportunity for study of a calcified intercellular material. For the study of all other intercellular materials it is essential to use young animals, preferably at the period of most rapid growth when the formation of connective tissue, bone and cartilage is most active. During rapid growth the 'turnover' of matrices, all of which have a collagenous foundation, is most rapid because of the remodelling of all supporting tissues, involving resorption and new deposition, a feature of growth easily followed in the skeleton but also apparent in ligaments of joints and the attachments of tendons.

Scurvy in the human infant becomes manifest quite soon by comparison with the adult. In the classic experiment of Crandon (Crandon, Lund \& Dill, 1940) I 32 days were required before the first clinical evidence-cutaneous hyperkeratotic papules - of scurvy appeared in an adult on a diet deficient only in ascorbic acid. Complete failure of healing following a skin biopsy occurred after 6 months of the ascorbic-acid free diet. Biochemists interested in quantitative studies of 'collagen' under conditions of dietary deficiency, or in the estimation of 'collagen turnover' by the use of heavy nitrogen or amino-acids containing radioactive carbon, should not fail to take into account the growth rate of their experimental animals.

The beauty of the 'scurvy and repair' experiment resides in the fact that it enables us to look at histological preparations and to state with certainty that a matrix-connective tissue, bone, cartilage, dentine-has been deposited during any desired period as determined by the time elapsing between administration of ascorbic acid and killing of the animal. The sequences of matrix deposition may be followed in the resumption of growth of all supporting tissues and in the repair of surgically-produced lesions in scorbutic guinea-pigs. The latter has certain advantages because in scurvy new capillary formation cannot take place, but fibroblasts do divide and migrate into blood clots after the fashion of growth in tissue cultures. Endothelial cells of capillaries at the periphery of blood clots resulting from excision of muscle divide and accumulate, forming cell clusters in which erythroblasts appear in conspicuous numbers (Wolbach, r933); this phenomenon is of dual interest because it takes place despite the complete deficiency of ascorbic acid and also because it provides an example of the experimental production of extramedullary haematopoiesis. The migration of fibroblasts into the blood clot results in appearances like those seen in plasma tissue-cultures of connective tissue explants, and affords opportunity to follow collagen formation, after ascorbic-acid therapy, about cells far removed from blood vessels and lymphatics.

The first material having staining properties of collagen completely surrounds such isolated cells and appears to be homogeneous (i.e. without demonstrable fibrils) resembling lightly stained amyloid. It is intimately applied to the cell body and to fibroglia fibril extensions beyond the apparent limits of the cell, and is not argyrophile. Next in sequence is the appearance of delicate fibrils which are argyrophile so that silver-impregnation methods give the appearance of there having been formed exceedingly delicate black fibrils embedded in a homogeneous collagenous matrix. More mature collagen of fibrillary structure in later periods of recovery 
does not impregnate with silver (Pl. I, 4,5,6). Identical sequences take place in the tissues of guinea-pigs early in the recovery from scurvy in the Gerïstmark zones of bones, and in the resumptions of osteoid deposits in the endochondral formation of bone and in the deposits of osteoid of endosteal and periosteal sources. This occurs even before osteoblasts--which, during the period of scurvy, have lost contact with bone and have become indistinguishable from fibroblasts - have re-acquired their distinctive cytological details.

Study of the two types of material - the organization of blood clots and the resumption of growth sequences in non-operated guinea-pigs--has revealed no indication that fibrin or any other substance present as a result of exudation or necrosis of cells, contributes to collagen formation, contrary to conclusions of Baitsell (1915, I916a,b) and Nageotte (1922, p. 47). Also, I could find no support for the observation of Lewis ( 1917 ), made from tissue-culture studies, that collagen fibrils are formed inside the connective cell and later appear as extracellular bundles. I described (Wolbach, 1933) in fibroblasts of scorbutic guinea-pigs, vacuoles which I conjectured were the source of an extracellular liquid and which recently were considered by Gersh \& Catchpole (1949) as a probable result of the accumulation of glycoprotein granules which they found to be increased in the fibroblasts in scorbutus (PI. I, 5). Their observations tempt me to make another conjecture, to the effect that the extracellular liquid, conspicuous in certain regions in experimental scorbutus, may be the result of failure of polymerization of glycoprotein, normally a constituent of the ground substance of connective tissue.

The first intercellular material about isolated fibroblasts in the repair of scurvy, which I described as a nonfibrillary material having the staining reactions of collagen and regarded as collagen (P1. I, 4,6), has been interpreted by Penney \& Balfour (I949) as mucopolysaccharide. Should their opinion be confirmed it would have an important bearing on the synthesis of collagen, particularly because these authors also described the appearance of argyrophile fibres (reticulum) as next in sequence in repair.

It is pertinent to suggest that the vacuoles containing acidophilic material present in osteoblasts engaged in bone formation are secretory in nature, which invites speculation regarding the nature of the contained material because of the metachromatic staining of osteoid (Penney \& Balfour, I949). In complete scurvy these vacuoles are not present in osteoblasts which have lost their distinctive appearance. They reappear rapidly within $3^{6} \mathrm{~h}$ after administration of ascorbic acid, coincidentally with resumption of normal cytological appearance and deposition of osteoid. In preparations of costochondral junction of normal growing guinea-pigs and in repair of scurvy, after acetic-acid Zenker fixation and staining either by Giemsa or eosin-methylene blue, these vacuoles contain minute basic-staining granules in a lightly stained pink background. Cortisone administration before and during repair produces no change (Wolbach \& Maddock, r952).

I do not regard a detailed account of the anatomic lesions of scurvy in man as pertinent to this occasion. I do maintain that, with one exception, all can be explained by failure of formation and maintenance of intercellular materials. The excep- 
tion is the follicular hyperkeratosis and defective formation of hair which precede the occurrence of petechial hemorrhages. Until the Crandon experiment (Crandon et al. 1940) there was ground for entertaining the possibility that the epithelial lesions might be the result of deficiency of other dietary essentials.

The repair of the lesions of scurvy is accomplished by the resumption of formation of intercellular materials. Numerous papers have been written by surgeons proving that fibrous-tissue union will not take place in wounds made upon the scorbutic guinea-pig, but does occur following ascorbic-acid administration. Such experiments in elucidation of the obvious were probably necessary to force attention of surgeons to the importance, to their patients, of adequate dietary regimens. In the infant this restoration is accompanied by the resumption of normal growth processes and if there has been deformity resulting from displacement of the epiphyseal ends of bones, eventually by complete return to normal relationships of epiphyses and diaphyses and normal growth patterns.

The effect of ascorbic-acid deficiency upon one kind of extracellular material having the function of support-the basement membranes of many important structures, renal tubules and glomeruli, alveoli of the lungs and all glandular organs-seems to be negligible, although I know of no study of basement membrane in scurvy utilizing the newer histological techniques which seem to be reliable and rather specific for the demonstration of basement membranes. I refer to the periodicacid treatment of sections, followed by leucofuchsin reagent, often called the McManus-Hotchkiss technique (Gersh \& Catchpole, 1949) and its modification by others. It is now quite well established that basement membranes are chemically related to ground substances-mucoproteins-and contain glycoprotein. The physical properties of basement membranes may be dependent upon the degree of polymerization of the glycoprotein (Gersh \& Catchpole, r949).

Although elastic fibres are generally regarded as products of connective-tissue cells, we have no information about their response to ascorbic-acid deficiency or in repair. I have failed, in rather cursory attempts, to see changes of elastic tissue in experimental animals. Aschoff \& Koch (r9r9) reported no changes in the elastica of blood vessels in human scurvy. Although more than 100 years have passed since elastica was identified as an elementary tissue (Hass, 1939a,b) its composition and source still remain enigmatical. Hass (1939c) has shown that cholesterol esters of highly unsaturated acids polymerize when injected into the subcutaneous tissue of guinea-pigs and, at lipid-aqueous interfaces, form membranes having many of the physical and tinctorial properties of elastica. He presents the hypothesis that proteins such as collagen, fibrin and marginal cytoplasm may contribute to the formation of lipoproteins and that the elastic tissue-like structures result from the condensation of lipoproteins. I mention Hass's work because it would be interesting to know if the membranes described by him would form in scorbutic guinea-pigs.

Much has been written about the adrenal glands in scorbutic guinea-pigs and the relation of ascorbic acid to the synthesis of cortical steriods and of late with particular reference to cortisone (Morgan, $195 \mathrm{I}$ ). The literature is too extensive and the conclusions too variable to warrant an attempt at a critical review, but no specific 
relationship has been proved (Pirani, 1952). A few high-lights have been considered by Wolbach \& Maddock (I952).

I do not believe that, as yet, distinctive histological features including lipids demonstrable by conventional techniques, have been found which would enable us to distinguish the guinea-pig adrenals in scorbutus from the enlarged adrenals of acute inanition (Blumenthal \& Loeb, I942) or those of hypervitaminosis A (Wolbach \& Maddock, I952; Wolbach, 1947). In each instance the adrenals are enlarged and there are extraordinary numbers of mitoses throughout the fascicular zone. Mitosis often appears to be arrested at the metaphase and frequently cells occur with dispersed and fragmented chromosomes. The cells of the fascicular zone are enlarged, pale, finely vacuolated, and contain less lipid than in normal adrenals. The glomerular zone becomes reduced in size (atrophic) and the cells small, without lipid droplets. In all three conditions guinea-pigs showing these adrenal changes have suffered marked retardation of growth and weight loss.

A morphologist cannot contemplate the arrest of formation of intercellular substances in scurvy and the dramatic effects of therapy, without being compelled to search in the publications of biochemists for information about the biological activities of ascorbic acid. This effort has been unrewarding on the whole and nothing has come to light in explanation of the suppression of collagen formation in the deficiency.

King (I950) summarizes the effects of ascorbic-acid deficiency as 'decreased phosphatase, esterase and oxidase enzyme content of tissues' and 'decreased capacity to metabolize the amino acids, tyrosine and phenylalanine'. King, in the light of current knowledge, makes the pertinent statement: 'The decided decreases in activity of many specific oxidative and hydrolytic enzymes in the tissues of scorbutic animals makes it evident that chemical disturbances induced by vitamin $\mathrm{C}$ deficiency are exceedingly complex and involve reactions that are characteristic of all living cells'.

The absence of phosphatase in the connective tissue in reparative efforts of wounds of scorbutic guinea-pigs and its prompt appearance in abundance following ascorbic-acid therapy have been beautifully shown by Danielli, Fell \& Kodicek (1945) and completely confirmed by Bunting \& White (1950).

A specific role of ascorbic acid as a coenzyme in the oxidation of tyrosine has beer affirmed (Sealock \& Goodland, 195I) and questioned (Anonymous, I953). In any event, the role of ascorbic acid as a coenzyme in the oxidation of aromatic aminoacids would seem not fundamental to the pathology of scurvy.

The resumption of formation of intercellular material in repair of scurvy suggests a possible approach to the solution of the question whether or not the ground substance or substances are involved in the formation of collagen. At least sequential application of histochemical techniques is possible as well as sequential studies by $\mathrm{X}$-ray diffraction analysis, electron microscopy and possibly microbiochemistry.

Perhaps before studies of this sort are attempted, further knowledge of the composition of ground substance should be obtained. Meyer (1947, 1950) emphasized mucopolysaccharides-hyaluronates--whereas Gersh (Gersh \& Catchpole, 
1949) has been concerned chiefly with the glycoprotein constituent. Both investigators acknowledge the presence or formation of polysaccharide-containing protein complexes. Meyer (1947) expressed the idea that fibril formation may result from the secretion by fibroblasts of hyaluronic acid and a precursor of collagen and a chondroitin sulphate. He suggests that with ageing the hyaluronate is more and more replaced by chondroitin sulphate. Schmitt and associates (Highberger, Gross \& Schmitt, I95I) entertain the idea that mucoprotein or a component thereof may be involved in the formation of collagen fibres, based upon electron-microscope study of the fibrils in the precipitate formed by the addition of mucoprotein to acidsoluble collagen of rat-tail tendons.*

The cursory digression I have made into the subject of composition of ground substances is not irrelevant to my subject. One purpose is to indicate the difficulties of the applications of histochemical methods, in which great progress has been made in recent years. Another is to indicate my realization that the study of ground substances in scurvy and repair has been neglected and offers opportunities for possible new insight of collagen formation. It is evident that in scurvy profound changes, probably the result of failure of polymerization, take place in the ground substances and that in repair coincidentally with, or possibly preceding, collagen formation normal ground substance reappears (Gersh \& Catchpole, r949; Penney \& Balfour, 1949; Klemperer, I950).

Cytological study of fibroblasts, osteoblasts and chondroblasts in scurvy and repair has lagged behind the study of their extracellular products. Recent developments in the techniques of separating nuclear and cytoplasmic structures, chromatin, mitochondria and microsomes (Claude, 1947-8) making them available for enzyme and other biochemical studies, offer enticing opportunities when considered in the light of the controllable conditions in the 'scurvy and repair' experiment. Other techniques now available for studies of collagen and ground substance are those of electron microscopy and X-ray diffraction analyses, both of which have contributed important advances in the study of the structure of the collagen fibril (Highberger et al. 195I; Astbury, 1950-I).

Some problems to be mentioned for which 'scurvy and repair' experiments may be useful are: (a) the differences in chemical composition of the various collagens, because the existence of such differences is already established by variations in solubilities and responses to hormones; (b) the role of connective tissue, particularly that of the skin, as a temporary repository in the maintenance of homeostasis of the blood, storage of water, salts, glucose, and dyestuffs-all reversible. The possible formation of irreversible compounds with ground substance and collagen has not been investigated. If such exist, their importance to the ageing process would be apparent. In a search for irreversible compounds of ground substances and collagen, it is conceivable that combinations might be formed following administration of suspected chemicals preceding or during resumption of intercellular-substance

* According to Meyer (1945) the inference is warranted that all of the components of ground substances are compounds containing hexosamine. The glycoproteins may be considered to be mucopolysaccharide protein compounds and to include serum albumin and serum globulins. 
formation in repair of scorbutus. Currently, the 'scurvy and repair' experiment has been employed for the study of the responses of connective tissues to cortisone administration with conflicting results; further studies are indicated (Wolbach \& Maddock, 1952).

It seems evident that the morphologist, the biochemist and the biophysicist should all be concerned with the progress of one another in their respective fields and, whenever possible, correlation of morphological, biochemical and biophysical information be made. Much knowledge has accumulated from each of these three fields of study but on the whole such knowledge is in the descriptive stage and awaits integration for insight into one aspect of the anatomy of life.

Histology, with the employment of conventional and special histochemical techniques will always remain indispensable and of increasing importance as new, more specific, and even quantitative methods appear for study of intercellular materials. Histology alone has enabled us to correlate the pathology and repair of scurvy with the suspension and restoration of normal growth processes.

\section{REFERENCES}

Anonymous (1953). Nutr. Rev. II, I7.

Aschoff, L. \& Koch, W. (1919). Scorbut, eine Pathologish-anatomische Studie. Jena: Gustav Fischer. Astbury, W. T. (1950-1). Harvey Lectures, 46, 3.

Baitsell, G. A. (1915). F. exp. Med. 21, 455 .

Baitsell, G. A. (1916a). F. exp. Med. 23, 739 .

Baitsell, G. A. (1916b). Amer. F. Physiol. 42, 608.

Baitsell, G. A. \& Mason, K. E. (1930). Amer. Rev. Tuberc. 21, 593.

Blumenthal, H. T. \& Loeb, L. (1942). Amer. F. Path. 18, 6r5.

Boyle, P. E., Bessey, O. A. \& Howe, P. R. (1940). Arch. Path. (Lab. Med.) 30, 90.

Bunting, H. \& White, R. F. (1950). Arch. Path. (Lab. Med.) 49, 590.

Claude, A. (1947-8). Harvey Lectures, 43, 121 .

Crandon, J. H., Lund, C. C. \& Dill, D. B. (r940). New Engl. F. Med. 223, 353.

Danielli, J. F., Fell, H. B. \& Kodicek, E. (I945). Brit. F. exp. Path. 26, 367.

Follis, R. H. Jr. (1943). Arch. Path. (Lab. Med.) 35, 579.

Follis, R. H. Jr. \& Berthrong, M. (1949). Fohns Hopk. Hosp. Bull. 85, 281.

Gersh, I. \& Catchpole, H. R. (1949). Amer. F. Anat. 85, 457.

Hass, G. M. (1939a). Arch. Path. (Lab. Med.) 27, 334.

Hass, G. M. (I939b). Arch. Path. (Lab. Med.) 27, ${ }_{5} 83$.

Hass, G. M. (I939c). Arch. Path. (Lab. Med.) 28, 177.

Highberger, J. H., Gross, J. \& Schmitt, F. O. (195I). Proc. nat. Acad. Sci., Wash., 37, 296.

Höjer, J. A. (1924). Acta paediat., Stockh., 3, suppl.

Hunt, A. N. (1941). Brit. F. Surg. 28, 436.

King, C. G. (1950). F. Amer. med. Ass. 142, 563 .

Klemperer, P. (1950). Amer. F. Path. 26, 505.

Lewis, M. R. (I9I7). Contr. Embryol. Carneg. Instn, 6, 45.

Lind, J. (1753). A Treatise of the Scurvy, ist ed. Edinburgh: Sands, Murray \& Cochran for A. Kincaid and $A$. Donaldson.

Meyer, K. (1945). Mucoids and Glycoproteins. In Advances in Protein Chemistry, Vol. 2, p: 249. [M. L. Anson and J. T. Esdall, editors.] New York: Academic Press.

Meyer, K. (1947). Physiol. Rev. 27, 335.

Meyer, K. (1950). Ann. N.Y. Acad. Sci. 52, 961 .

Morgan, Agnes F. (195I). Vitam. \& Horm. 9, 16r.

Nageotte, J. (1922). L'Organisation de la Matière dans ses Rapports avec la Vie. Paris: Felix Alcan.

Penney, J. R. \& Balfour, B. M. (1949). F. Path. Bact. 6r, I71.

Pirani, C. L. (1952). Metabolism, I, 197.

Pirani, C. L. \& Levenson, S. M. (1953). Proc. Soc. exp. Biol., N.Y., 82, 95.

Sealock, R. R. \& Goodland, R. L. (1951). Science, x14, 645.

Walter, R. (1748). Anson's Voyage Round the World. 
S. BURT WOLBACH. EXPERIMENTAL SCURVY. ITS EMPLOYMENT FOR THE STUDY

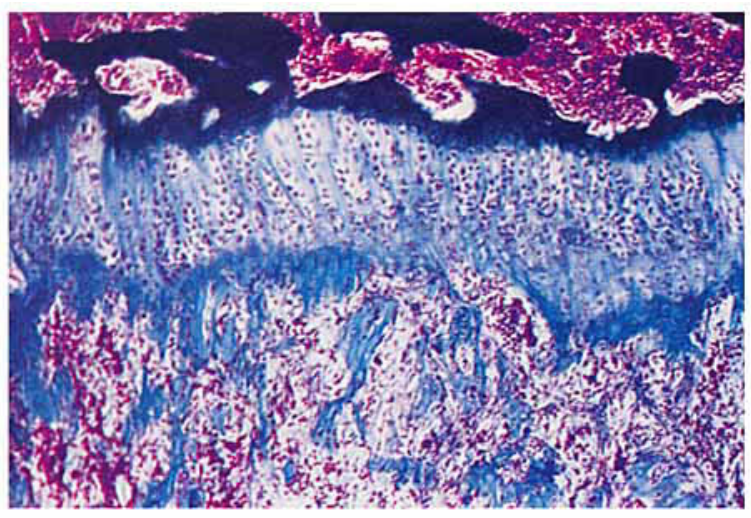

I

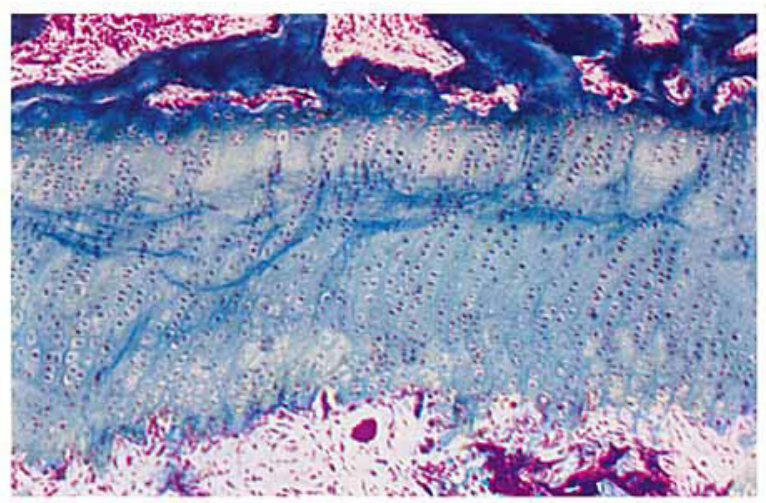

2

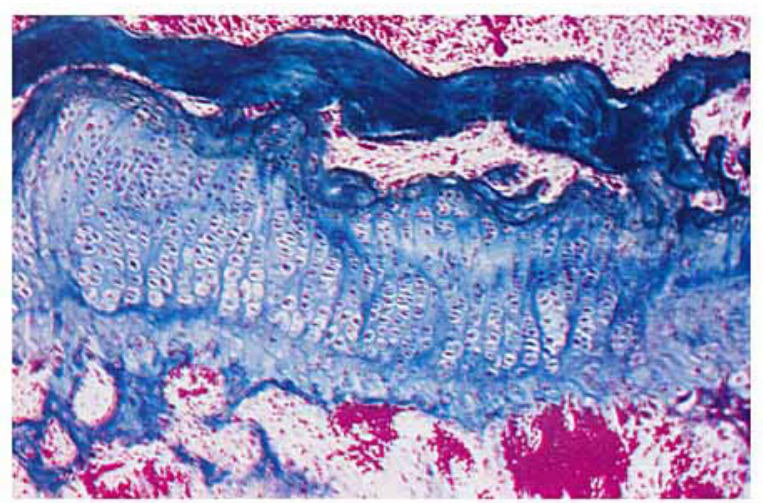

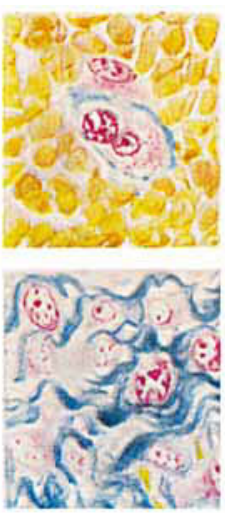
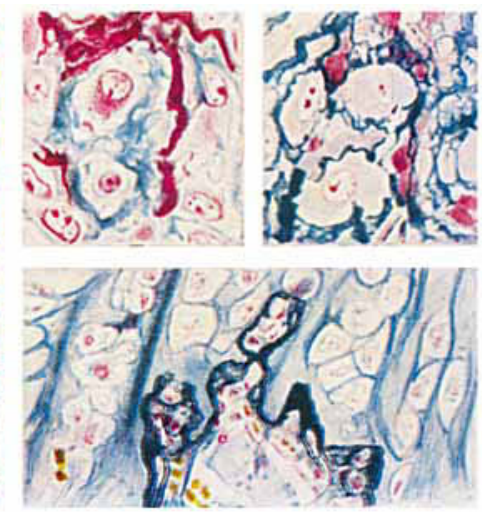

4
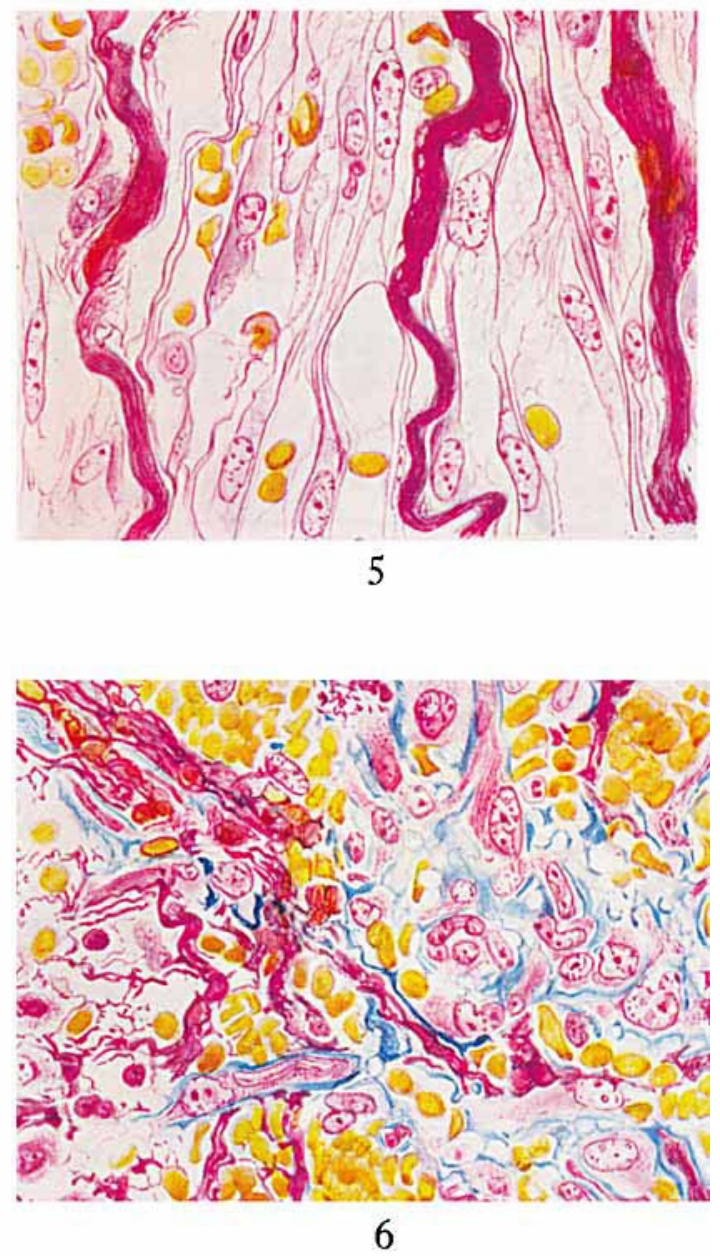

Proceedings of The Nutrition Society, Vol. 12, No. 3 
Wolbach, S. B. (1933). Amer. F. Path. 9, suppl. p. 689.

Wolbach, S. B. (1947). F. Bone ft. Surg. 29, I71.

Wolbach, S. B. \& Howe, P. R. (1926). Arch. Path. (Lab. Med.) I, I.

Wolbach, S. B. \& Maddock, C. L. (1952). Arch. Path. (Lab. Med.) 53, 54.

\section{EXPLANATION OF PLATE}

I. Proximal epiphyseal cartilage of tibia. Scorbutic guinea-pig showing failure of matrix formation. Mallory's connective-tissue stain.

2. Repair after $72 \mathrm{~h}$, following ascorbic-acid administration. Proximal epiphyseal cartilage, tibia.

3. Repair after $96 \mathrm{~h}$, proximal epiphyseal cartilage, tibia, guinea-pig. To show approximately normal cartilage cells and matrix.

4. Upper left. To show collagen deposition in relation to an isolated cell deep within a blood clot. Repair after $72 \mathrm{~h}$, following excision of muscle.

Middle upper. Same preparation to show collagen deposition of cells which have penetrated fibrin strands. Repair after $72 \mathrm{~h}$.

Upper right. A corresponding field, reticulum stain, repair of a blood clot after $72 \mathrm{~h}$.

Lozver left. Repair of a blood clot after $96 \mathrm{~h}$. To show collagen deposition in a group of fibroblasts which have not yet assumed their normal morphology.

Lower right. Resumption of deposition of matrix in endochondral bone formation. Reticulum stain. Recovery period of $40 \mathrm{~h}$.

5. Fibroblasts in relation to fibrin strands in organization of a blood clot in absolute scorbutus. Note prominence of fibroglia fibrils and cytoplasmic vacuoles in fibroblasts. No stainable collagen or argyrophile fibrils present. Guinea-pig operated on the 23 rd day of deficient diet, killed on the 33 rd day.

6. To illustrate collagen formed in organization deep within a blood clot, following $42 \mathrm{~h}$ ascorbic-acid therapy. Note the homogeneous appearance of the collagen. 